|Araştırma Makalesi / Research Article |

\title{
Görsel Sanatlar Eğitiminde Disiplinler Arası Yaklaşım: STEAM ${ }^{1}$
}

\section{Interdisciplinary Approach in Visual Arts Education: STEAM}

\section{İsmail HELVACI ${ }^{2}$, Meliha YILMAZ}

\author{
Anahtar Kelimeler \\ görsel sanatlar eğitimi \\ disiplinler arası yaklaşım \\ STEM \\ STEAM
}

Keywords
visual arts education
interdisciplinary
approach
STEM
STEAM

Başvuru Tarihi/Received 20.09.2020

Kabul Tarihi /Accepted 05.10.2020

\begin{abstract}
Öz
Bu çalışmada, Fen, Teknoloji, Mühendislik ve Matematik disiplinlerine Sanatın entegre edilmesiyle temellenen STEAM yaklaşım uygulamalarıyla verilen Görsel Sanatlar Eğitimi'nin bu yaklaşımı oluşturan disiplinlere yönelik görüşlere etkisinin belirlenmesi amaçlanmıştır. 2017-2018 eğitim öğretim yılı bahar döneminde Batı Karadeniz'de bir ilde merkez ilçeye bağlı bir devlet okulunda gerçekleştirilen çalışma Görsel Sanatlar dersi kapsamında 6 hafta sürmüştür. Araştırmanın nitel araştırma ile modellenmiş, durum çalışması türlerinden açıklayııı durum çalışması kapsamında gerçekleştirilmiştir. Çalışma grubunu 6 . Sınıfta öğrenim gören 25 öğrenci oluşturmaktadır. Çalışma verileri uygulama öncesinde ve sonrasında yarı yapılandırıımış görüşmeler ile toplanmış, yarı yapılandırılmış görüşme formu verileri ise içerik analizi ile çözümlenmiştir. Araşıırma bulgularından hareketle, uygulama öncesi ve sonrası STEAM ve STEAM disiplinlerine yönelik görüşlerine bakıldığında STEAM yaklaşımına dayalı etkinlikler ile gerçekleştirilen süreç öncesi öğrencilerin STEAM ve STEAM disiplinlerine yönelik bilgilerinin yeterli düzeyde olmadığı belirlenmiștir. Uygulama sonrası ise katılımcıların Fen, Teknoloji, Mühendislik, Sanat ve Matematik disiplinlerine yönelik derinleşen ifadelerde bulundukları; Sanat-Fen-Mühendislik disiplinlerinlerinin entegrasyonundan bahsettikleri; sanata yönelik kapsamlı görüşlere sahip oldukları belirlenmiştir. Önemli bulgulardan biri de sanata yönelik olumlu bir görüş gelişim/değişimi belirlenmesidir. Bulgular ışığında gerçekleştirilen uygulamanın STEAM disiplinlerine yönelik görüş gelişiminde yardımcı etkisi olduğu saptanmıştır. STEAM'in çerçevesinin netleşmesini ve uygulama örneklerinin zenginleşmesi için araştırmacılara ve program yapıcılara öneriler sunulmuştur.

\section{Abstract}

This study intents to determine the effect of the application of the STEAM approach, which is formed by integrating Art into Science, Technology, Engineering and Mathematics disciplines, within the scope of Visual Arts Education on the views towards STEAM disciplines. The study, conducted in a state school in the central district in a province of the Western Black Sea in the spring semester of 2017-2018 education, lasted 6 weeks as part of the Visual Arts class. The research was modeled with qualitative research and carried out within the context of descriptive case study, one of the types of case studies. The study group consists of 25 students studying in the $6^{\text {th }}$ grade. Study data were collected with semi-structured interviews before and after the implementation, and semi-structured interview form data was analyzed with content analysis. Based on the research findings, when looking at students' views on STEAM and STEAM disciplines before and after the implementation; it was determined that the students' knowledge about STEAM and STEAM disciplines was not at a sufficient level before the process carried out with activities based on STEAM approach. After implementation, it has been determined that the participants made in-depht statements about Science, Technology, Engineering, Art and Mathematics disciplines; they mentioned about the integration of Art-Science-Engineering disciplines; and they have comprehensive views on art. One of the important findings is the determination of a positive opinion development/change towards art. It was determined that the implementation carried out in the light of the findings had a supportive effect on the development of opinion towards STEAM disciplines. Suggestions have been presented to researchers and program developers to clarify the framework of STEAM and to enrich the implementation examples.
\end{abstract}

\footnotetext{
${ }^{1}$ Bu çalışma Prof. Dr. Meliha YILMAZ danışmanlığında İsmail HELVACI tarafından hazırlanan doktora tezinin bir bölümünden üretilmiştir.

${ }^{2}$ Sorumlu Yazar, Kastamonu Üniversitesi, Eğitim Fakültesi, Güzel Sanatlar Eğitimi, Kastamonu, TÜRKiYE; https://orcid.org/0000-0002-5778-4278

${ }^{3}$ Gazi Üniversitesi Eğitim Fakültesi, Güzel Sanatlar Eğitimi, Ankara, TÜRKiYE; https://orcid.org/0000-0002-7732-2660
} 


\section{Introduction}

The interdisciplinary approach is based on the logic of using different fields that constitute the basis of the curriculum together. The interdisciplinary approach, which has been used in different ways in education for many years, contributes to the formation/development of high-level mental skills in solving complex problems. One of these interdisciplinary approaches is STEM. STEM concept is formed from the initials of Science, Technology, Engineering and Mathematics disciplines. The most up-to-date version of the STEM approach is STEAM, which is formed by integrating Art into the STEM discipline. STEAM consists of the initials of the Science, Technology, Engineering, Art and Mathematics disciplines. STEAM is an education policy that spreads from Korea to the world education systems. STEM aims to create a society that presents products for the solution of possible problems that will exist in the future by addressing today's problems with a realistic perspective. STEAM, on the other hand, is a process that get involved at this point and creates originality by adding design process and aesthetic measures to this product. One of the most important arguments of the STEAM existence process is that the STEAM approach, which is formed by the addition of the discipline of Art, is not much different from STEM.

When the literature is examined, it is seen that STEAM studies are mostly studied by researchers in the field of science and mathematics, and the framework of implementations that can serve as an example for the integration of these disciplines is not clearly defined. Lack of studies to illuminate these points about the STEAM approach is considered to be an important problem. Studies in the field of STEM and STEAM have been carried out with science-based educators and researchers, this field has not been studied in art-oriented courses that provide aesthetics and design skills, and this area has not been studied by those people. All these information mentioned are the reasons for the realization of the study.

In the light of this information, the aim of the study is to determine the effect of STEAM implementations to be applied in the Visual Arts course on the views on STEAM disciplines and the opinions on the STEAM approach. In this study, which can be an example for the integration of STEM with different disciplines and implementation areas of STEAM, the answer to the question of "How do the views of the group in which the STEAM approach is applied in the Visual Arts Course change before and after the application?" has been sought.

\section{Method}

The study was carried out with descriptive case study, one of the types of case studies within the scope of qualitative method. The study group consists of 25 students who are studying in the $6^{\text {th }}$ grade in a state school in the central district of a province in the Western Black Sea in the spring semester of the 2017-2018 academic year. Data were collected through semi-structured interviews. The activities applied in the study were developed by the researcher and the implementation process was carried out by the researcher. The Visual Arts course in which the implementation was carried out was 1 lesson hour per week. The implementation process of the activities continued for 6 weeks and one activity was applied every week. In five of the activities, four disciplines of STEAM were used, while all disciplines are used in one activity. Science, Mathematics, Information Technologies and Visual Arts Course curriculum outcomes were taken into consideration in the activities prepared. The data from the interviews conducted within the scope of the research were analyzed with content analysis. The data were analyzed by inductive analysis. The inter-coder consistency percentage was calculated as 87.15.

\section{Result and Discussion}

In the study, it was tried to determine the effect of the intruction given with the activities developed within the scope of STEAM, which is an interdisciplinary approach to be applied within the scope of the Visual Arts course, on the views on the disciplines that form STEAM. Before the implementation, the participants were categorized as being eclectic, if they were between know-not know; and being naïve if they have wrong or no opinion in their views on STEAM disciplines. This means that students either did not know or did not fully define STEAM before implementation. Those who cannot define STEAM are those who have heard this concept in various scientific activities or speeches and could not make sense of what they heard. In other words, opinions on STEAM and its sub-disciplines are very superficial.

When the opinions were examined after the implementation, there was a deepening and when the expressions were examined carefully, there was an improvement in the definitions. With the implementation, the participants developed opinions about STEAM and its disciplines. These rootings are clearly seen with the codings formed in Science, Mathematics, Technology and Engineering disciplines. In the sub-dimension of art, a perspective on art has been developed, formations such as color knowledge have been formed and the idea of the art-aesthetic connection has been seeded in their minds. The development of perception is also observed in the attitude towards art. In this context, it can be said that the study provides artistic thought formations in the consciousness of individuals. As a result of the research, it was found that the visual arts education delivered with the activities developed within the scope of the STEAM approach not only brought about positive changes in the views on art, but also brought about the development/changes of opinion towards other disciplines that form STEAM. It has been suggested that a formation of structure and program arrangement should be made in which STEAM discipline branch teachers can work in coordination. In addition, it is thought that STEAM's weaknesses and strengths should be determined by working in different disciplines. 


\section{GíRiş}

Eğitimin bireylerde yaratıcı düşünme, analitik bakış açısı ve tasarım becerisi kazandırabilmek temellerinde sürekli değişmekte olduğu bilinmektedir. Bu temeller farklı disiplinlerin bir arada kullanılması ile köklendirelebileceğinden, uluslararası düzeyde de farklı disiplinlerin bir arada kullanması eğilimi oluşmaktadır (Milli Eğitim Bakanlığı [MEB], 2018, s.4). Disiplinler arası eğitim de ivmeli bir şekilde disiplin kombinasyonları ile sürekli eğitim için en iyi aramaya yönelik evrilmektedir.

Disiplinler arası yaklaşım öğretim programlarının alt yapısı oluşturan farklı alanların birlikte kullanılması mantığına dayanmaktadır. Eğitim içerisinde uzun yıllardır farklı şekillerde kullanılan disiplinler arası yaklaşım karmaşık problemlerin çözümlenebilmesinde (Condee, 2004), üst düzey zihinsel becerilerinin oluşması/gelişmesinin sağlanmasında katkı sağlamaktadır (Condee, 2004; Haring \& Kelner, 2015; Michelsen, 2015). Başka bir ifade ile çağımızın en önemli gereklilikleri olan araştıran, sorgulayan, yaratıcı, karar verebilen bireylerin oluşturulması (Brophy, Klein, Porstmore \& Rogers, 2008; Tyler-Wood, Knezek \& Christensen, 2010) disiplinler arası yaklaşımın etki alanı kapsamındadır. Disiplinler arası yaklaşımın en güncel örneklerinden biri de STEM'dir. STEM kavramı Fen, Teknoloji, Mühendislik ve Matematik disiplinlerinin İngilizce baş harflerinden (Science, Technology, Engineering, Mathematics) oluşturulmuştur. Şekil 1'de görüldüğü STEM disiplinleri birbirleri ile ilişkili ve işbirliklidir.

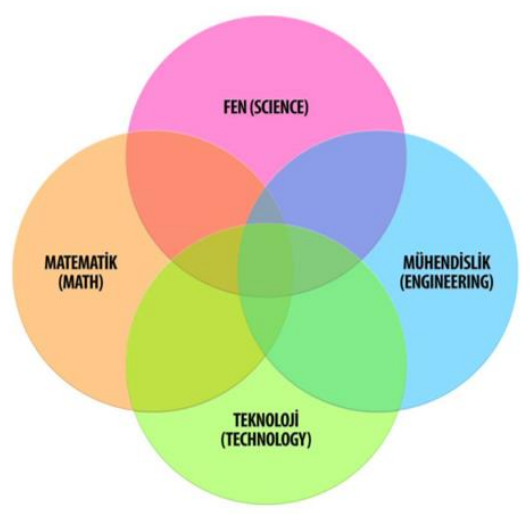

Şekil 1. STEM yaklaşımı disiplinleri (Akgündüz vd., 2015)

STEM yaklaşımı ilk kez 2001 yılında Amerika Birleşik Devletleri (ABD) Ulusal Bilim Kurulu yöneticisi Judith A. Ramaley tarafından dile getirilmiştir (Yıldırım \& Altun, 2015). ABD’nde doğan bu yaklaşım hızla Uzak doğu ve Avrupa ülkelerindeki eğitim sisteminde kendine yer edinmiştir (Yılmaz, Koyunkaya, Güler \& Güzey, 2017). Ulusal eğitimimizde ise 2018 yılında öğretim programlarımızda gerçekleştirilen revizelerle eğitim sistemimize dahil edilmiştir (MEB, 2018, s.4-11). STEM ile güncellenen öğretim programında Fen ve Mühendislik disiplinlerinin birlikte kullanımı ders kitaplarındaki etkinliklerde görülmektedir.

STEM yaklaşımı yalnızca belirli bir zaman kesitinde verilebilecek bir yapıda değildir. Okul öncesinden yüksek öğretime kadar esnek bir uygulama alanı vardır (Çorlu, Caprao \& Caprao, 2014). STEM farklı disiplinleri ile iş birliğine açık ve yeni kompleks yapılara dönüşebilen bir disiplinler arası yaklaşımdır. Bu kapsamda girişimcilik (STEM-Entrepreneurship, STEM+E) ve programlama (STEMComputing, STEM+C) disiplinleriyle ülke ihtiyaçları düşünülerek eğitim politikalarının ve programlarının geliştirilmesine ihtiyaç vardır (Akgündüz vd., 2015). STEM yaklaşımının en güncel hali ise STEM disiplinine Sanatın entegre edilmesiyle oluşan STEAM'dir.

STEAM Fen, Teknoloji, Mühendislik, Sanat ve Matematik disiplinlerinin İngilizce başharflerinden oluşmaktadır. STEAM Kore'den Dünya eğitim sistemlerine yayılan bir eğitim politikasıdır. Bu bütüncül disiplinlerarası eğitim Yakman tarafından 2010'da geliştirilmiştir (Ayvacı \& Ayaydın, 2017; Batı, Çalışkan, \& Yetişir, 2017; Braund, 2015; Yakman, 2010). STEM günümüz sorunlarını gerçekçi bir bakış açısıyla ele alınarak gelecekte var olacak muhtemel sorunların çözümüne yönelik ürünler ortaya koyan bir toplumu şimdiden oluşturmayı hedeflemektedir. STEAM ise tam bu noktada devreye giren ve oluşturulan bu ürüne tasarımsal süreç ile estetik ölçüler ekleyerek özgünlük meydana getiren bir süreçtir. STEAM varoluş sürecinin en önemli argümanlarından biri de Sanat disiplininin eklenmesiyle oluşan STEAM yaklaşımı düşünme şeklinin, STEM'den çok da farklı olmadığıdır (Watson \& Watson, 2013).

STEAM, STEM ile ulaşılmak istenen düzeyin üstünde konumlanmaktadır. Sanat disiplini içerisinde estetik, el işi becerisi, özgür tasarım süreci gibi içerikler yer almaktadır (Yakman, 2008). Yakman’ın (2008) piramidi bu konuda açıklayıcıdır: 


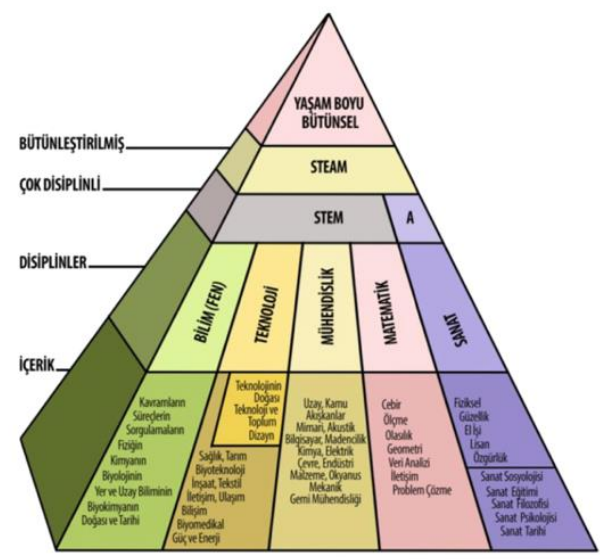

Şekil 2. STEAM eğitimi (Yakman, 2008)

Etkili bir STEM içeriği oluşturulması için Sanat'a yer verilmesi büyük önem taşımaktadır. STEAM eğitiminde yer verilmesi gereken içerikler şu şekilde sıralanmaktadır (Park \& Ko, 2012):

1. Mevcut öğretim programlarının STEM yaklaşımını oluşturan disiplinler arasında bir karmaşa oluşturulmadan bir entegrasyon sürecine sokulmalıdır. Ayrıca, bütünleştirilmiş düşünme ya da kaynaştırılmış düşünme etkinlikleri STEAM ile kullanılabileceği gibi STEAM'in her disiplinine yönelik olarak ayrı ayrı da çalışılabilir.

2. STEAM yaklaşımının yaratıcılık gelişimini kazandırmaya yönelik eğitim verilmesi aşamasında fen, teknoloji ve mühendislik disiplinlerine yönelik düşünme stratejilerinin kazanımlarının hedeflenmesi gereklidir. STEAM eğitiminde bireylerin temel bilimsel teorilerine yönelik bilgi ve becerilerin kazandırılması ve bu bilimsel teorileri teknoloji gelişiminde kullanılmalarına yönelik bir düşünce geliştirmelidir. STEAM disiplinlerinin gerçek hayatla ilişkilendirilmesi gerekmektedir.

3. Hedefleri kazandırmada başarılı olan ve yaratıcılık geliştiren bir eğitim STEAM yaklaşımının temelidir ve bunun sağlanması için eğitimcilere yaratıcı araçlar temin edilmesine ihtiyaç vardır. Eğitimcilere yaratıcılığı geliştirici yöntemler, araçlar, etkinlikler geliştirilmesi gerekmektedir. STEAM ile sıklıkla anılan yaratıcı etkinlik kavramının da STEAM yaklaşımı ile entegrasyonu önemlidir.

4. STEAM eğitiminin odak noktalarından biri büyük resmi algılayabilmek becerisinin kazandırılmasıdır.

5. Gelişen dünya ile rekabet edebilecek bir fen, teknoloji ve mühendislik eğitimi insana özgü özellikler göz ardı edildiğinde çok anlamsız olabilir. Eğitim felsefesinin de değişen bu koşullara uyum sağlayacak şekilde bir başkalaşım süreci geçirmelidir.

6. STEAM eğitimi sadece fen, teknoloji, mühendislik, sanat ve matematik disiplinlerinin yanı sıra politika, çevre, toplum ve ekonomi disiplinleri ile de tümleşik bir süreçte eğitim sistemine katılmalıdır.

7. STEAM eğitiminin kilit noktalarından biri mühendislik disiplini için sözü edilen bütüncül tasarımdır. Bütüncül tasarım, bilim insanları ve geleceğe yön verecek mühendisler yetiştirmekten daha derin bir kavramdır. Bilimsel etik, sosyal gelişim, liderlik ve etkili iletişim yeteneğinin de sürece dâhil olduğu yoğun bir yetenek geliştirme tasarımını ifade etmektedir.

Alan yazında STEM disiplinlerine Sanat'ın entegrasyonuna yönelik çalışmalar bulunmaktadır ve bu çalışmalar incelendiğinde disiplinlerin bilgi, algı, tutum ve yaratıcılık üzerine etkisinin incelendiği görülmektedir (Yakman, 2008; Kwona, Namb \& Lee, 2011; Sousa \& Pilecki, 2013; Jin, Chong \& Cho, 2013; Kim, Ko, Han \& Hong, 2014; Henriksen, 2014; Jeong \& Kim, 2015; Gülhan \& Şahin, 2016; Rolling, 2016; Sochacka, Guyotte \& Walther, 2016; Ayvacı \& Ayaydın, 2017; Cook, Bush \& Cox, 2017; Cook \& Bush, 2018). Ulusal çalışmalarımız incelendiğinde ise STEAM ile ilgili yapılan çalışma sayısının sınırlı olduğu görülmektedir (Batı, Çalışkan \& Yetişir, 2017; Özkan \& Umdu-Topsakal, 2017; Gülhan \& Şahin, 2018a; Gülhan \& Şahin, 2018b). STEAM çalışmalarının sadece fen ve matematik alanındaki araştırmacılar tarafından çalışımasının yanı sıra bu disiplinlerin entegrasyonuna örnek teşkil edilebilecek uygulamaların çerçevesinin de net olarak belirlenmediği görülmektedir. STEAM yaklaşımı ile ilgili bu noktaları aydınlatacak çalışmalar olmaması önemli bir problem olarak düşünülmektedir. STEM ve STEAM alanında yapılan çalışmalar bilim temelli eğitimci ve araştırmacılar ile gerçekleştirilmiş, estetik ve tasarım becerisini kazandıran sanat odaklı derslerde ve bu alan çalışmalar yapan tarafından çalışılmamıştır. Bahsi geçen tüm bu bilgiler çalışmanın gerçekleştirilmesinin gerekçeleridir.

$\mathrm{Bu}$ bilgiler ışığından çalışmanın amacı, Görsel Sanatlar dersi içerisinde uygulanacak STEAM uygulamalarının STEAM disiplinlerine yönelik tutum ve STEAM yaklaşımına yönelik düşüncelere etkisinin belirlenmesidir. STEM'in farklı disiplinlerle entegrasyonuna ve STEAM'in uygulama alanlarına yönelik örnek olabilecek bu çalışmada aşağıdaki araştırma sorusuna cevap aranmıştır:

1) Görsel Sanatlar Dersinde STEAM yaklaşımının uygulandığı grubun STEAM disiplinlerine yönelik görüşleri uygulama öncesi ve sonrası nasıl değişmektedir? 
YÖNTEM

\section{Araştırmanın Modeli}

Çalışmanın nitel yöntem kapsamında durum çalışması temelinde gerçekleştirilmiştir. Durum çalışmaları, daha ayrıntılı ve geniş bir tanımlama yapılmasında ve bağlamsal analiz kullanılarak daha kompleks bir durumu açıklamada başvurulan yöntemdir (Yin, 2013). Araştırmada, durum çalışması türlerinden biri olan açıklayıcı durum çalışması kullanılmışır. Açıklayııı durum çalışmaları betimsel olmakla beraber durumla ilgili bilgi elde edilmesine/verilmesine yardımcı olur (Yin, 2009; Yılmaz \& Yanarateş, 2020).

\section{Çalışma Grubu}

Çalışma grubunu 2017-2018 eğitim yılı bahar döneminde Batı Karadeniz'de bir ilin merkez ilçesine bağlı bir devlet okulunda 6 . sınıfta öğrenim görmekte olan 25 öğrenci oluşturmaktadır. Çalışma grubu özelliklerine ilişkin bilgiler Tablo 1'de yer almaktadır.

Tablo 1. Çalışma grubuna ait özellikler

\begin{tabular}{lcccc}
\hline & Sınıf & Kız & Toplam & Erkek \\
\hline Çalışma Grubu & 6 & 13 & 12 & 25 \\
\hline
\end{tabular}

Katılımcıların öğrencilerin aritmetik ortalamaları 73-98, 10-12 yaş aralığındadır. Araştırmanın nitel kısmının verilerinin elde edilmesinde, uygulamanın gerçekleştirildiği 25 öğrencinin uygulama öncesi ve sonrası görüşlerine başvurulmuştur. Akademik ortalamaları 76-98 aralığında, 13 kız 12 erkek ve yaşları 10-12 yaş aralığında değişen katılımcı grubu ile çalışılmıştır. Katılımcılar Ö1, Ö2, Ö3...Ö25 şeklinde kodlanmıştır.

\section{Veri Toplama Araçları}

Araştırmada toplanan veriler uygulama öncesi yarı yapılandırılmış görüşme formu ile, uygulama sonrasında ise görüşme formuna ek bir soru ilave edilerek yapılan yarı yapılandırılmış görüşmelerle gerçekleştirilmiştir. Görüşme sorularının oluşturulmasında nitel araştırmalar konusunda uzman bir akademisyenden görüş alınmıştır. Uygulamaya başlamadan önce uygulamanın gerçekleştiği devlet okulundan farklı bir okulda 4 katılımcı ile pilot ön görüşmeler yapılmıştır. Öğrencilerin etkinliklerle ilgili kazanımları ve deneyimleri ile ilgili cevapları verebilmeleri kriteri göz önünde bulundurularak, görüşme sorularında gerekli revizeler yapılmış, sonda sorular oluşturulmuştur. Görüşmeler yaklaşık 15 dakika sürmüştür.

\section{Uygulama Süreci}

Çalışmada uygulanan etkinlikler araştırmacı tarafından geliştirilmiş ve uygulama süreci araştırmacı tarafından yürütülmüştür. Buna ek olarak çalışma boyunca "Fen Bilimi Uzmanı" titri ile fen eğitimi doktoru bir eğitimciden destek alınmıştır. Uygulamanın bilimsel ayağının sağlıklı ilerlemesi ve araştırmayı riske edebilecek bilgi ihtiyaçları öngörülerek bu önlem uygun görülmüştür. Uygulamanın gerçekleştirildiği Görsel Sanatlar dersi haftalık 1 ders saatidir ve ortaokul müfredatında zorunlu ders kapsamındadır. Araştırma sürecinde 8 hafta katılımcılar ile bir zaman geçirilmiş, bu sürecin ilk ve son haftası ön test ve son test verileri toplanmıştır. Etkinliklerin uygulama süreci 6 hafta boyunca devam etmiş ve her hafta bir etkinlik uygulanmıştır. Etkinliklerin uygulama süreci ve etkinliklerin kapsadığı STEAM disiplinleri Şekil 3’te açıklanmıştır.

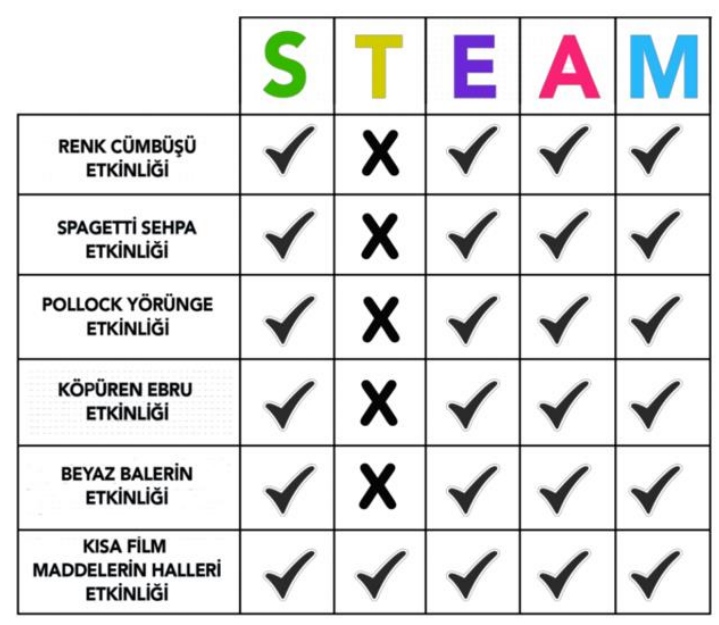

Şekil 3. Uygulama etkinliklerinin kapsadıkları STEAM disiplinleri 
Etkinliklerin beş tanesinde STEAM'in dört disiplini kullanılırken, birinde ise tüm disiplinler kullanılmaktadır. Hazırlanan etkinliklerde Fen Bilimleri, Matematik, Bilişim Teknolojileri ve Görsel Sanatlar Dersi öğretim programları kazanımları dikkate alınmıştır. Uygulama süreci etkinlikleri içerikleri şu şekildedir:

Tablo 2. Uygulama süreci etkinlikleri ve içerikleri

\begin{tabular}{|c|c|}
\hline Etkinlik & Etkinlik İçeriği \\
\hline Renk Cümbüşü Etkinliği & $\begin{array}{l}\text { Bu etkinlik STEAM yaklaşımının Fen, Mühendislik, Sanat ve Matematik alanlarına yönelik kazanımlar hedeflemektedir. Fen } \\
\text { disiplininde ışık, tam ve yarı gölge; Mühendislik disiplininde ürün tasarımı; Matematik disiplininde uzaklık, daire, alan; } \\
\text { Sanat disiplininde ise ana ve ara renk, estetik kavramını kazanarak tasarımlarını yapmaları beklenir. Bu etkinlikte işbirlikli } \\
\text { çalışmadan yararlanılmaktadır. }\end{array}$ \\
\hline Spagetti Köprüsü Etkinliği & $\begin{array}{l}\text { Bu etkinlik STEAM yaklaşımının Fen, Mühendislik, Sanat ve Matematik alanlarına yönelik kazanımlar hedeflemektedir. Fen } \\
\text { disiplininde ağırık merkezi, denge; Mühendislik disiplininde ürün tasarımı; Matematik disiplininde uzunluk, geometrik } \\
\text { şekiller ve matematiksel işlemler; Sanat disiplininde ise ana ve ara renk, estetik kavramını kazanarak tasarımlarını } \\
\text { yapmaları beklenir. Bu etkinlikte işbirlikli çalışmadan yararlanılmaktadır. }\end{array}$ \\
\hline Pollock Yörünge Etkinliği & $\begin{array}{l}\text { Bu etkinlik STEAM yaklaşımının Fen, Mühendislik, Sanat ve Matematik alanlarına yönelik kazanımlar hedeflemektedir. Fen } \\
\text { disiplininde dönme hareketi, yer çekimi, salınım, gezegenler; Mühendislik disiplininde ürün tasarımı; Matematik } \\
\text { disiplininde geometrik şekiller ve matematiksel işlemler; Sanat disiplininde ise ana ve ara renk, estetik kavramını kazanarak } \\
\text { tasarımlarını yapmaları beklenir. Bu etkinlikte işbirlikli çalışmadan yararlanılmaktadır. }\end{array}$ \\
\hline Köpüren Ebru Etkinliği & $\begin{array}{l}\text { Bu etkinlik STEAM yaklaşımının Fen, Mühendislik, Sanat ve Matematik alanlarına yönelik kazanımlar hedeflemektedir. Fen } \\
\text { disiplininde fiziksel ve kimyasal tepkimeler; Mühendislik disiplininde ürün tasarımı; Matematik disiplininde geometrik } \\
\text { şekiller ve matematiksel işlemler; Sanat disiplininde ise ana ve ara renk, estetik kavramını kazanarak tasarımlarını } \\
\text { yapmaları beklenir. Bu etkinlikte işbirlikli çalışmadan yararlanılmaktadır. }\end{array}$ \\
\hline Beyaz Balerin & $\begin{array}{l}\text { Bu etkinlik STEAM yaklaşımının Fen, Mühendislik, Sanat ve Matematik alanlarına yönelik kazanımlar hedeflemektedir. Fen } \\
\text { disiplininde elektromanyetik kuvvetler, mıknatıs; Mühendislik disiplininde ürün tasarımı; Matematik disiplininde geometrik } \\
\text { şekiller ve matematiksel işlemler; Sanat disiplininde ise ana ve ara renk, estetik kavramını kazanarak tasarımlarını } \\
\text { yapmaları beklenir. Bu etkinlikte işbirlikli çalışmadan yararlanılmaktadır. }\end{array}$ \\
\hline Kısa Film: Maddenin Halleri & $\begin{array}{l}\text { Bu etkinlik STEAM yaklaşımının Fen, Teknoloji, Mühendislik, Sanat ve Matematik alanlarına yönelik kazanımlar } \\
\text { hedeflemektedir. Fen disiplininde maddenin halleri; Teknoloji disiplininde teknolojik bir araç kullanımı, eğitimde teknoloji } \\
\text { entegrasyonu ve program kullanımı; Mühendislik disiplininde ürün tasarımı; Matematik disiplininde geometrik şekiller ve } \\
\text { matematiksel işlemler; Sanat disiplininde tasarım, estetik kavramını kazanarak tasarımlarını yapmaları beklenir. Bu } \\
\text { etkinlikte işbirlikli çalışmadan yararlanılmaktadır. }\end{array}$ \\
\hline
\end{tabular}

\section{Verilerin Analizi}

Araştırma kapsamında gerçekleştirilen görüşmelerden veriler içerik analizi ile analiz edilmiştir. İçerik analizi, eldeki yazılı dökümanların temel içeriklerinin ve içerdikleri mesajların özetlenmesi ve belirtilmesi işlemidir (Cohen, Manion \& Morrison, 2007). İçerik analizinde, dokümanlardan elde edilen nitel araştırma verilerinin işlenmesi, verilerin kodlanması, temaların bulunması, kodların ve temaların düzenlenmesi, bulguların tanımlanması ve yorumlanması şeklinde dört aşama bulunmaktadır (Yıldırım \& Şimşek, 2013). İlk basamak için, görüşme formları müdahalede bulunulmadan bilgisayar ortamında yazılı hale getirilmiştir. Uygulama öncesi 15 sayfa, uygulama sonrası ise 28 sayfa olmak üzere toplam 43 sayfalık yazılı doküman elde edilmiştir. Hiçbir değişiklik yapılmadan bilgisayar ortamına aktarılan görüşme verileri, başka bir araştırmacı tarafından da gözden geçirilmiş, görüşmenin deşifre edilmiş kayıtları, analize uygunluk için günlük konuşma dilinden arındırılmış, anlaşılabilirliği için düzenlenmiştir (Coolican, 2009; Kvale, 1996). Sonrasında görüşme, dökümanlaştırılma kurallarına göre yeniden düzenlenmiştir (Mayring, 2000). Veriler tümevarım analizi ile çözümlenmiştir. Elde edilen veriler, yazar ve nitel çalışma uzmanınca birbirinden bağımsız olarak okunmuş ve bireysel kod ve kategoriler oluşturulmuştur. Bireysel olarak oluşturulan bu kod ve kategoriler karşılaştırılmış, fikir birliğine varılana kadar kayıtlar incelenmiştir. Çalışmanın güvenilirliğini belirlemek amacıyla bireysel veri çözümleri arasında, Miles \& Huberman'ın (1994) uyum yüzdesi formülü kullanmıştır (Uyum Yüzdesi = (Uzlaşma) / (Uzlaşma + Uzlaşmama) X 100). Uyum Yüzdesi 87,15 olarak hesaplanmıştır. Her bir araştırma problemine ilişkin uygulama öncesi ve sonrası kodlama ve kategorileştirme yapılmış, alıntılara yer verilerek bulgular sunulmuştur.

\section{BULGULAR}

Görsel Sanatlar Eğitimi dersinin STEAM yaklaşımı etkinlikleri ile gerçekleştirildiği çalışma grubunun STEAM disiplinlerine yönelik görüşleri sorgulanmıştır. Görüşmelerden elde edilen verilerin analizine ait kodlama ve kategori yoğunlukları Tablo 3’de verilmiştir. 


\begin{tabular}{|c|c|c|c|c|c|c|c|c|c|}
\hline 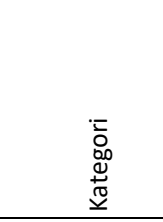 & $\begin{array}{l}\text { D } \\
\stackrel{0}{ }\end{array}$ & 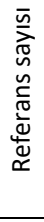 & 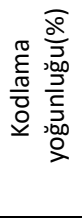 & 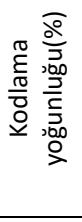 & 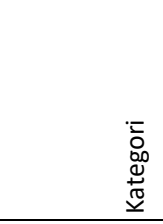 & $\begin{array}{l}\overline{0} \\
\underline{0}\end{array}$ & 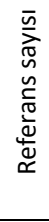 & 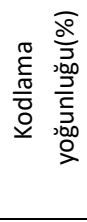 & 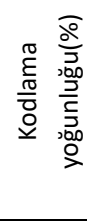 \\
\hline \multirow{10}{*}{$\begin{array}{l}\text { Eklektik } \\
\text { (Yarı Bilgili) }\end{array}$} & \multirow{3}{*}{ Mühendis } & \multirow{3}{*}{5} & \multirow{3}{*}{17,8} & \multirow{10}{*}{71,4} & \multirow[t]{2}{*}{ Fen/Bilim } & $\begin{array}{c}\text { Bilim insanı gibi } \\
\text { olma }\end{array}$ & 15 & 7,9 & \multirow{4}{*}{26,3} \\
\hline & & & & & & Bilime katkı & 16 & 8,4 & \\
\hline & & & & & \multirow[t]{2}{*}{ Teknoloji } & Teknolojik araç & 8 & 4,2 & \\
\hline & \multirow{4}{*}{$\begin{array}{l}\text { Öğretim } \\
\text { Program } \\
\text { değişimi }\end{array}$} & \multirow{4}{*}{6} & \multirow{4}{*}{21,4} & & & Teknoloji gelişimi & 11 & 5,8 & \\
\hline & & & & & \multirow{3}{*}{ Mühendislik } & Ürün yapma & 21 & 11 & \multirow{3}{*}{17,3} \\
\hline & & & & & & Tamir yapma & 7 & 3,7 & \\
\hline & & & & & & Fen kitabı etkinliği & 5 & 2,6 & \\
\hline & \multirow{3}{*}{ Bilim şenliği } & \multirow{3}{*}{9} & \multirow{3}{*}{32,1} & & \multirow{3}{*}{ Sanat } & Sanatçı bakış açısı & 23 & 12,1 & \multirow{3}{*}{32.1} \\
\hline & & & & & & Estetik & 18 & 9,5 & \\
\hline & & & & & & Renkler & 20 & 10,5 & \\
\hline & & & & \multirow{3}{*}{28,6} & \multirow{3}{*}{ Matematik } & Hesaplama & 12 & 6,3 & \multirow{3}{*}{24,3} \\
\hline Naif (Bilgisiz) & Bilmeme & 8 & 28,6 & & & $\begin{array}{c}\text { Geometrik şekilleri } \\
\text { kullanma }\end{array}$ & 18 & 9,5 & \\
\hline & & & & & & Ölçme & 16 & 8,4 & \\
\hline
\end{tabular}

STEAM yaklaşımına dayalı etkinlikler ile verilen sanat eğitiminin verildiği grubun uygulama öncesi Naif ve Eklektik; uygulama sonunda ise STEAM'in alt boyutlarını içerecek Fen/Bilim, Teknoloji, Mühendislik, Sanat ve Matematik kategorilerini oluşturmuşlardır. STEAM yaklaşımına dayalı etkinlikler uygulanmadan önce bu disiplinlerine yönelik bilgisiz ya da bilgili kabul edilemeyecek görüşlerde bulunmuşlardır. Naif kategorisinde STEAM'e yönelik hiçbir bilgisi olmayanlar ve bir cevapta bulunmayan; Eklektik kategorisinde STEAM'e yönelik doğru olmayan ya da eksik bilgilere sahip olan kodlamalar mevcuttur. Buna ilişkin öğrenci ifadelerinden bazıları şu şekildedir:

"STEAM ne bilmiyorum [=bilmeme] ... Hiç duymadım." (Ö3-Uygulama Öncesi)

“Deney yapılan çadırda [=bilim şenliği] dönen bir top vardı. Ona STEM deneyi dediler” (Ö23-Uygulama Öncesi)

"Bilim şenliğinde [=Bilim şenliği] duvarda yazıyordu... Mühendis [=Mühendis] olmaktır buluş yapmaktır. (Ö11-Uygulama Öncesi)

“Yeni fen kitabında [Öğretim programı değişikliği] var orada gördüm. (Ö3- Uygulama Öncesi)

"Hayatımda ilk kez duydum [=bilmeme]" (Ö12-Uygulama Öncesi)

"Oyun oynanan sitedir [=bilmeme]" (Ö19-Uygulama Öncesi)

“Öğretmenimizin bizi götürdüğü yerdeki [=Bilim şenliği] şeylerdir" (Ö17-Uygulama Öncesi)

Uygulama sonrası STEAM'e yönelik STEAM'in disiplinlerine paralel olarak Fen/Bilim, Teknoloji, Mühendislik, Sanat ve Matematik kategorileri oluşmuştur. STEAM yaklaşımına dayalı etkinlikler sonrası uygulama öncesine göre kod ve kategorilerin değiştiği ve gelişerek derinleştiği görülmektedir. Bu tespit araştırmanın en kıymetli bulgularındandır. STEAM'e yönelik bilgi eksikliği gözlemlenen katılımcılar, STEAM'e ve tüm disiplinlerine yönelik atıfta bulunmuşlardır. Katılımcılar bilimden, bilimdeki ilerlemeden, bilim insanının bilime etkisinden; teknolojideki ilerlemenin sağladığı gelişim ivmelenmesinden, mühendisliğin bir araç gibi kullanımından ve ders kitaplarında yer alan fen-mühendislik-girişimcilik etkinliklerine yönelik farkındalıktan; sanata yönelik ilgi ve farkındalıktan söz etmişlerdir. STEAM kavramı içerisinde sanatçı, estetik kavramı, ürün ve tasarım çağrışımları saptanmıştır. Görsel sanatlar dersi içerisinde matematik hesaplamalar ve geometrik şekillere de atıfta bulunmuşlardır. Tüm bu bulgulara ilişkin uygulama sonrası öğrenci ifadelerinden bazıları şu şekildedir:

"Mühendis olmak bir şey yapmaktır [=ürün yapma] ... Ama öyle düz değil renkli şeyler [=renkler] yapan hangi rengin yakışacağına karar verebilen [=estetik] kimsenin yapmadığını yapan bir mühendis (Ö11-Uygulama Sonrası) 
"Bizi ileri götürür [=bilimde katkı] eğlenceli biridir teknolojik şeyler yapar [=teknolojik araç] her şeyi aynı anda yapmaya çalışır düşünmeye bir ressam gibi [=sanatçı bakış açısı] çalışır." (Ö13-Uygulama Sonrası)

"Kendimi büyük bir ressam [=sanatçı bakış açısı] gibi hissettim. Ama bir sürü şey yapabilen... Hesaplama [=hesaplama] yapabilen bir ressam gibi." (Ö15-Uygulama Sonrası)

"Bu şekilde bilimde faydalı [=bilime katkı] olabilirim." (Ö20-Uygulama Sonrası)

"Eğer yaptığım etkinliklerde bir de motor olsaydı dönseydi gece lambası [=teknolojik araç] olurdu...çok güzel olurdu bunu yaptıysam onu da yapardım [=ürün yapma]." (Ö16-Uygulama Sonrası)

\section{TARTIŞMA}

Çalışmada, Görsel Sanatlar dersi kapsamında uygulanmak üzere disiplinler arası bir yaklaşım olan STEAM kapsamında geliştirilen etkinlikler ile verilen eğitimin, STEAM'i oluşturan disiplinlere yönelik görüşlere etkisi belirlenmeye çalışılmıştır. Görsel sanatlar eğitiminde STEAM yaklaşımı kullanıımasının katılımcılarda meydana getirdiği değişimlerin derinlemesine incelenmesi için uygulama öncesi ve sonrası görüşleri alınmıştır. Uygulama öncesi ve sonrası görüşler içerik analizi ile çözümlenmiştir. Oluşan kod ve kategoriler incelendiğinde, uygulamanın etkisine ilişkin olumlu yorumlarda bulunulabilir. Uygulama öncesi katılımcılar STEAM disiplinlerine yönelik görüşlerinde bilme-bilmeme arasında ise eklektik, yanlış ya da hiçbir fikre sahiplerse de naif olarak kategorileştirilmişlerdir. Bu, uygulamadan önce öğrencilerin STEAM'i ya hiç bilmedikleri ya da tam olarak tanımlayamadıkları anlamına gelmektedir. STEAM'i tanımlayamayanlar çeşitli bilimsel aktivitelerde ya da konuşmalarda bu kavramı duymuş ve duyduklarını anlamlandıramamış olanlardır. Başka bir ifade ile STEAM ve alt disiplinlerine olan görüşler çok yüzeyseldir.

Uygulama sonrasında görüşler incelendiğinde, bir derinleşme ve ifadeler dikkatle incelendiğinde tanımlamalarda iyileşme olduğu saptanmıştır. Uygulama ile birlikte katılımcılar STEAM ve disiplinlerine yönelik görüşler geliştirmişlerdir. Fen, Matematik, Teknoloji ve Mühendislik disiplinlerinde oluşan kodlamalarla bu köklenmeler açıkça görülmektedir. Sanat alt boyutunda ise sanata bir bakış açısı gelişmiş, renk bilgisi gibi temeller oluşmuş ve sanat-estetik bağlantısının fikri zihinlerinde tohumlanmıştır. Bu bulgu Yakman (2008)'ın STEAM piramidin en tepe noktasında konumlandııılığından araştırmanın en önemli sonuçlarındandır. Sanata yönelik tutum içerisinde algı gelişimi de gözlemlenmektedir. Bu bağlamda, çalışmanın bireylerin bilinçlerinde sanatsal düşünce oluşumları sağladığı söylenebilir. Sanatla bütünleştirilmiş bir öğretimin bireylerde duygu, düşünce gelişim sağlaması (Nimmo, 1998), araştırmanın bu bulgusunu desteklemektedir. Bireylerin eğitim süreçlerinde sadece matematik ve fen derslerinin kabartıldığı bir öğretim programı almaları hangi alanda olursa olsun ilerlemelerini sağlamaya yeterli değildir (Buyurgan \& Buyurgan, 2012). Bu bağlamda, araştırmanın da geliştirmiş olduğu sanatsal kazanımlar değerlidir. STEM'in evrilmiş hali olarak kabul edilebilecek STEAM yaklaşımı alanında yapılan çalışmalarda da bu disiplinlere yönelik olumlu değişimlerin meydana geldiği tespit edilmiştir (Kim, Nam \& Lee, 2014; Kim, Ko, Han \& Hong, 2014; Kong \& Ji, 2014; Kong \& Huo, 2014; Özkan \& Umdu-Topsakal, 2017; Gülhan \& Şahin, 2018a; Gülhan \& Şahin 2018b).

STEAM fen ve matematik alanında köklenen disiplinlerin özgünlükteki etkililiğinin sağlanabilmesi için çok önemlidir (Bequette \& Bequette, 2012). Katılımcı görüşlerindeki değişimin ve özellikle sanatla ilgili olan bu gelişimin görsel sanatlar eğitimi kapsamında sağlanabilmesi kıymetlidir. Bu bulgu STEAM etkisi göz önünde bulundurularak iyi bir eğitim süreci tasarımı gerekliliğini de (Baki \& Karadeniz, 2013), destekler niteliktedir.

\section{SONUÇ VE ÖNERILER}

Araştırma sonucunda, STEAM yaklaşımı kapsamında geliştirilen etkinlikler ile verilen görsel sanatlar eğitiminin sanatla ilgili görüşlerde olumlu değişimler meydana getirmesinin yanı sıra STEAM'i oluşturan diğer disiplinlere yönelik görüş gelişim/değişimleri de meydana getirmiştir. STEAM yaklaşımı ile verilen eğitimin STEAM disiplinlerine yönelik görüş gelişim/değişim sağladığı belirlenmiştir. Burada odaklanılması gereken sonuç Görsel Sanatlar eğitimi dersinde aynı anda fen, matematik, mühendislik, teknoloji ve sanat disiplinlerinde gelişme kaydedilebilmiş olunmasıdır. Görsel sanatlar dersi bütüncül bir bakış açısı ile diğer derslerle iş birliği yapacak şekilde tasarlandığında eğitimde işlevsel olduğu ve boyut kazandığı görülmektedir. Bu sonuçlar ışığında şu önerilerde bulunulmuştur:

\section{Program Yapıcılara Yönelik Öneriler}

Görsel Sanatlar dersi öğretim programı iki boyutlu sanatsal çalışmalar ve renk bilgisi düzleminde kendine yer edinebilmiştir. 2023 Eğitim Vizyonu hedefleri ile bağdaşır şekilde çağı yakalamaya yönelik revize edilebilir. STEAM kapsamındaki dersler arası gerçekleştirilebilecek iş birliği öğrenmede kesintisizlik de sağlayabilir. 2023 Eğitim Vizyonunun haberdar ettiği Tasarım-Beceri Atölyelerinde gerçekleşecek tasarım süreçlerinde estetik değerleri verebilecek sanatı odağa almak vizyonun hedeflediklerin gerçekleşmesine yardımcı olabilir.

Uygulamanın olumlu sonuçlar vermesindeki önemli etkenlerden biri çalışma yürütücülerinin özverisidir. Teorinin pratiğe yansıması için STEAM'in her bir disiplin uzmanı ile koordineli çalışılmışıı. Bilinmektedir ki branşlar arası benzer koordineli çalışma yapabilmek MEB'in dinamikleri arasında çoğu zaman mümkün olmayabilir. STEAM disiplinlerini bünyesinde bulunduran tek bir öğretmenlik branşı da yoktur. Bu kapsamda branş öğretmenleri arası iş birliği sağlanabileceği bir platforma yönelik çalışmalar yapılabilir. 


\section{Araştırmacılara Yönelik Öneriler}

STEM'in diğer türevleri gibi STEAM de çoğunlukla sayısal altyapııı bakış açısı ile çalışıımaktadır. Özellikle yaklaşımın fen eğitimin tekelinde algısı oluşmaktadır. Bunu yıkmak amacıyla STEAM kendisini oluşturan tüm disiplinlerce çalışılabilir. Bu sayede yaklaşımın zayıf ve güçlü yönleri belirlenerek iyileştirmeler yapabilme imkanı doğabilir. STEAM yaklaşımının çerçevesini netleştirmek ve etkililiğini sınamak maksadıyla bu alanda daha fazla çalışma yapılması önerilmektedir.

\section{KAYNAKÇA}

Akgündüz, D., Aydeniz, M., Çakmakçı,G., Çavaş,B., Çorlu, M.S., Öner, T.,\& Özdemir,S. (2015). A report on STEM Education in Turkey: A provisional agenda or a necessity?. İstanbul Aydın Üniversitesi STEM Merkezi ve Eğitim Fakültesi. http://www.aydin.edu.tr/belgeler/IAU-STEMEgitimi-Turkiye-Raporu-2015.pdf sayfasından erişilmiştir.

Ayvacı, H. Ş \& Ayaydın, A. (2017). Bilim teknoloji mühendislik sanat ve matematik (STEAM). (Ed. Çepni, S.) Kuramdan Uygulamaya STEM+A+E Eğitimi, (s. 115-130). Ankara: Pegem Akademi.

Barrett, B. S., Moran, A. L., \& Woods, J. E. (2014). Meteorology meets engineering: An interdisciplinary STEM module for middle and early secondary school students. International Journal of STEM Education, 1(1), 1-6.

Batı, K., Çalışkan, i \& Yetişir, M. İ. (2017). Fen eğitiminde bilgi işlemsel düşünme ve bütünleştirilmiş alanlar yaklaşımı (STEAM). Pamukkale Üniversitesi Eğitim Fakültesi Dergisi, 41, 91-103.

Baki, A. \& Karadeniz, M. H. (2013). Okul öncesi eğitim programının matematik uygulama sürecinden yansımalar. Kastamonu Eğitim Dergisi, 21(2), 619-636.

Bequette ,J.W. \& Bequette,M. (2012). A place for art and design education in the STEM conversation. Art Education. 65(2), $40-47$.

Brophy, S., Klein, S., Portsmore, M., \& Rogers, C. (2008). Advancing engineering education in P-12 classrooms. Journal of Engineering Education, 97(3), 369- 387.

Buyurgan, S. \& Buyurgan, U. (2012). Sanat eğitimi ve öğretimi. Ankara: Pegem Akademi

Condee, W. F. (2004). The future is interdisciplinary. Teatre Survey, 2, 235-240.

Coolican, H. (2009). Research methods and statistics in psychology. (5th Edition). London: Hodder Education.

Cook, K.L. \& Bush, S. B. (2018). Design thinking in integrated STEAM learning: Surveying the landscape and exploring exemplars in elementary grades. School Science and Mathematics, 118, 93-103.

Cook, K. L., Bush, S. B, \& Cox, R. (2017). From STEM to STEAM: Incorporating the arts in roller coaster engineering. Science and Children, 54(6), 86-93.

Çorlu, M. A. \& Aydin, E. (2016). Evaluation of learning gains through integrated STEM projects. International Journal of Education in Mathematics, Science and Technology, 4(1), 20-29.

Çorlu, M. S., Capraro, R. M., \& Capraro, M. M. (2014). Introducing STEM education: Implications for educating our teachers in the age of innovation. Education and Science, 39(171), 74-85.

Cotabish, A., Dailey, D., Robinson, A., \& Hughes, G. (2013). The effects of a STEM intervention on elementary students' science knowledge and skills. School Science and Mathematics, 113(5), 215-226.

Gülhan, F. \& Şahin, F. (2016). Fen-teknoloji-mühendislik-matematik entegrasyonunun (STEM) 5. sınıf öğrencilerinin bu alanlarla ilgili algı ve tutumlarına etkisi. International Journal of Human Sciences, 13(1), 602-620.

Gülhan, F., \& Şahin, F. (2018a). STEAM (STEM+Sanat) eğitimine yönelik etkinlik uygulaması: Aynalar ve ışık. Araştırma Temelli Etkinlik Dergisi, $8(2), 111-126$.

Gülhan, F., \& Şahin, F. (2018b). STEAM (STEM+Sanat) etkinliklerinin 7. sınıf öğrencilerinin akademik başarı, STEAM tutum ve bilimsel yaratıcılıklarına etkisi. International Journal of Human Sciences, 15(3), 1675-1699.

Lam, P., Doverspike, D., Zhao, J., Zhe, J., \& Menzemer, C. (2008). An evaluation of a STEM program for middle school students on learning disability related ieps. Journal of STEM education, 9(1-2), 21-29.

Haring, D. \& Kelner, T. (2015). Why we got serious about interdisciplinary teaching. Educational Leadership, 73(4), 68-72.

Henriksen, D. (2014). Full STEAM ahead: Creativity in excellent STEM teaching practices. The STEAM Journal, 1(2), 1-7.

Jeong, S. \& Kim, H. (2015). The Effect of a Climate Change Monitoring Program on Students' Knowledge and Perceptions of STEAM Education in Korea. EURASIA Journal of Mathematics, Science \& Technology Education, 11(6), 1321-1338.

Jin, Y., Chong, L. M. \& Cho, H. K. (2012). Designing a robotics-enhanced learning content for STEAM Education 2012. 9th International Conference on Ubiquitous Robots and Ambient Intelligence (URAI) Daejeon, Korea. 
Judson, E., \& Sawada, D. (2000). Examining the effects of a reformed junior high school science class on students' math achievement. School Science and Mathematics, 100(8), 419-425.

Katz, G. (1998). What can we learn from Reggio Emilia? In C. Edwards, L. Gandini, \& G. Forman (Eds.), The hundred languages of children (2nd ed., pp. 27-45). Norwood, NJ: Ablex.

Kim, D.H., Ko, D.G., Han, M.J. \& Hong, S.H., (2014). The effects of science lessons applying STEAM education program on the creativity and Interest levels of elementary students. Journal of the Korean Association for Science Education, 34(1), 43-54.

Knezek, G., Christensen, R., Tyler-Wood, T., \& Periathiruvadi, S. (2013). Impact of environmental power monitoring activities on middle school student perceptions of STEM. Science Education International, 24(1), 98-123.

Kong, X., Dabney, K. P., \& Tai, R. H. (2014) The association between science summer camps and career interest in science and engineering. International Journal of Science Education, 4(1), 54-65.

Kvale, S. (1996). Interviews an introduction to qualitative research interviewing. Thousand Oaks, California: Sage.

Kwona, S., Namb, D. \& Lee, T. (2011). The effects of convergence education based steam on elementary school students' creative personality. T. Hirashima et al. (Eds.) (2011). Proceedings of the 19th International Conference on Computers in Education. Chiang Mai, Thailand: AsiaPacific Society for Computers in Education

Mayring, P. (2000). Nitel sosyal araştırmaya giriş (Çev. A. Gümüş ve M. S. Durgun). Adana: Baki.

Michelsen, C. (2015). Mathematical modeling is also physics-interdisciplinary teaching between mathematics and physics in Danish upper secondary education. Physics Education, 50(4), 489-494.

Milli Eğitim Bakanlığı. (2018). Fen bilimleri dersi öğretim programı (ilkokul ve ortaokul 3, 4, 5, 6, 7 ve 8 . sınıflar). .07 Kasım 2018 tarihinde http://ttkb.meb.gov.tr/www/guncellenen-ogretimprogramlari/icerik/151 sayfasından erişilmiştir.

Milli Eğitim Bakanlığı Yenilik ve Eğitim Teknolojileri Genel Müdürlüğü. (2015). STEM Eğitim Raporu. 24 Kasım 2018 tarihinde http://yegitek.meb.gov.tr/STEM_Egitimi_Raporu.pdf sayfasından erişilmiştir.

Nimmo, J. (1998). Connections: Using the project approach with 2-and 3-year-olds in a university laboratory school. In C. Edwards, L. Gandini, \& G. Forman (Eds.), The hundred languages of children (pp. 251-26 7). Norwood, NJ: Ablex.

Özkan, G. \& Umdu Topsakal, U. (2017). Examining students' opinions about STEAM activities. Journal of Education and Training Studies, 5(9), 116-123.

Park, N., \& Ko, Y. (2012, September). Computer education's teaching-learning methods using educational programming language based on STEAM education. In IFIP International Conference on Network and Parallel Computing (pp. 320-327). Springer, Berlin, Heidelberg.

Robinson, A., Dailey, D., Hughes, G., \& Cotabish, A. (2014). The effects of a science-focused STEM intervention on gifted elementary students' science knowledge and skills. Journal of Advanced Academics, 25(3), 189-213.

Rolling, J. H. (2016). Reinventing the STEAM Engine for Art + Design Education. Art Education, 69(4), 4-7.

Sochacka, N. W., Guyotte, K. W. \& Walther, J. (2016). Learning together: A collaborative autoethnographic exploration of STEAM (STEM+theArts) education. Journal of Engineering Education, 105(1), 15-42.

Sousa, D. A., \& Pilecki, T. (2013). From STEM to STEAM: Using brain-compatible strategies to integrate the arts. Thousand Oaks, CA: Corwin.

Tal, T., Krajcik, J. S \& Blumenfeld, P. C. (2006). An observational methodology for studying group design activity. Research in Engineering Design, 2(4), 722-745.

Tenaglia, T. (2017). STEAM curriculum: Arts education as an integral part of interdisciplinary learning. Messiah College Curriculum and Instruction Research Project, Parkway.

Watson, A. D., \& Watson, G. H. (2013). Transitioning STEM to STEAM: Reformation of engineering education. Journal for Quality \& Participation, $36(3), 1-4$.

Watter, J. J., \& Diezman, C. M. (2013). Community partnerships for fostering student interest \& engagement in STEM. Journal of STEM Education: Innovations \& Research, 14(2), 47-55.

Yakman, G.(2010). What is the point of STE@M? - A Brief Overview, 24 Kasım 2018 tarihinde http://www.steamedu.com/20062010 Short WHAT IS STEAM.pdf sayfasından erişilmiştir.

Yakman, G, (2008). ST¿@M Education: an overview of creating a model of integrative education. Pupils Attitudes Towards Technology. 2008 Annual Proceedings: Netherlands.

Yakman, G. \& Hyonyong, L. (2012). Exploring the Exemplary STEAM Education in the U.S. as a Practical Educational Framework for Korea. Journal of The Korean Association For Science Education, 32(6), 1072- 1086.

Yazar, T., Aslan, T., \& Şener, S. (2014). Sanat eğitimi sorunu olarak ülkemizde ilk ve orta öğretim kurumlarında sanat eğitimine olan ilgisizlik sebepleri. Ondokuz Mayıs Üniversitesi Eğitim Fakültesi Dergisi, 33(2), 593-605. 
Yıldırım, A. (1996). Disiplinler arası öğretim kavramı ve programlar açısından doğurduğu sonuçlar. Hacettepe Üniversitesi Eğitim Fakültesi Dergisi, $12,89-94$.

Yıldıım, B. \& Altun, Y. (2015). STEM eğitim ve mühendislik uygulamalarının fen bilgisi laboratuar dersindeki etkilerinin incelenmesi. El-Cezeri Journal of Science and Engineering, 2(2), 28-40.

Yıldııı, B. \& Altun, Y. (2018). STEM eğitimi üzerine derleme çalışması: Fen bilimleri alanında örnek ders uygulanmaları. M. Riedler et al. (Ed.) in VI. International Congress of Education Research 2014: Hacettepe University.

Yıldırım, B. \& Selvi, M. (2017). An experimental research on effects of STEM applications and mastery learning. Journal of Theory and Practice in Education, 13(2), 183-210.

Yılmaz, A., \& Yanarateş, E. (2020). Determination of Metaphorical Perceptions of Prospective Teachers on the Concept of "Water Pollution" Through Triangulation. Kastamonu Education Journal, 28(3), 1500-1528. https://doi.org/10.24106/kefdergi.722554

Yılmaz, H., Koyunkaya, M. Y., Güler, F., \& Güzey, S. (2017). Fen, Teknoloji, Mühendislik, Matematik (STEM) eğitimi tutum ölçeğinin Türkçe'ye uyarlanması. Kastamonu Eğitim Dergisi, 25(5), 1787-1800.

Yin, R. K. (2009). Case study research: Design and methods. SAGE Publications

Yin, R.K. (2013). Validity and generalization in future case study evaluations. Evaluation, 19(3), 321-332. 